\author{
EVS24 \\ Stavanger, Norway, May 13-16, 2009
}

\title{
Development of Power Capacitors for New Model Battery Forklift
}

\author{
Makoto Shimizu ${ }^{1}$, Yuichi Tanaka ${ }^{1}$, Yoshihiro Fujita ${ }^{1}$, Shuichi Kitagawa ${ }^{2}$, \\ Toshiaki Nagase ${ }^{3}$, Kazuyoshi Kontani ${ }^{3}$ \\ ${ }^{1}$ NIPPON CHEMI-CON CORP., 185-1, Marunouchi, Yabuki-machi, Nishi-Sirakawa-gun, Fukushima 969-0235, \\ Japan,shimizu@nippon.chemi-con.co.jp \\ ${ }^{2}$ EUROPE CHEMI-CON CORP., ${ }^{3}$ TOYOTA INDUSTRIES CORP.
}

\begin{abstract}
Forklift for industrial field is mostly used in closed area like warehouses or factories. Therefore, the emission issue of forklift is more serious than that of usual vehicles outdoors. And forklift is required the compact size and high power driven system for the efficient work in a limited area.

In EVS20 at Long Beach, we presented a paper about the power capacitors for battery forklift for the first time. This time, we will present our latest development for new model Battery Forklift which is far superior to the conventional type.

AC motor driven system newly developed by TOYOTA INDUSTRIES CORP. provides higher performance and smaller size than the conventional system by installing higher quality and smaller AC controller and AC motor driver.

NIPPON CHEMI-CON CORP. developed Power Capacitors in the inverter circuit. The total volume of new capacitors reached nearly half ( $\Delta 47 \%$ ) compared with the conventional type by reducing the internal resistance and adopting optimized cooling structure.

In this paper, we will describe the upgrade of TOYOTA 48V Battery Forklift, AC motor driven system and the development of Power Capacitors for the inverter use.
\end{abstract}

Keywords: Forklift, AC Motor, Inverter, Capacitor

\section{Toyota 48V Battery Forklift}

\subsection{Specification and Appearance}

\begin{tabular}{|l|l|}
\hline Model & 8 FBET15 \\
\hline Load capacity & $1.5($ ton $)$ \\
\hline Dimensions & L2782 $\times \mathrm{W} 1050 \times \mathrm{H} 2055(\mathrm{~mm})$ \\
\hline Battery & $\begin{array}{l}\text { Type: Lead-acid battery } \\
\text { Voltage: } 48 \mathrm{~V}, \text { Capacity: } 440 \mathrm{Ah}(5 \mathrm{~h})\end{array}$ \\
\hline Motors & $\begin{array}{l}\text { For run: } 6.6 \mathrm{~kW} \times 2 \\
\text { For loading: } 11.7 \mathrm{~kW}\end{array}$ \\
\hline
\end{tabular}

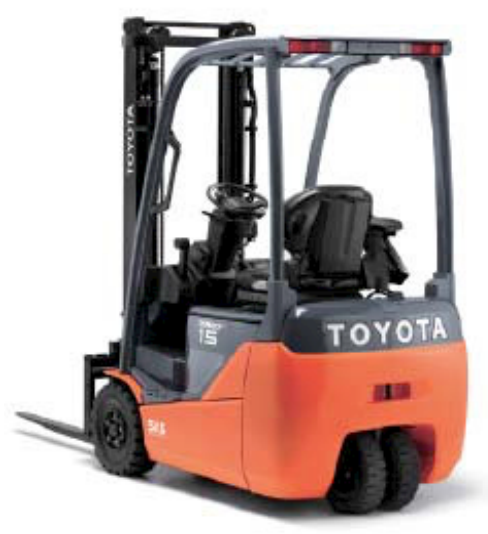




\subsection{Features of New Battery Forklift}

- Downsizing of vehicle size with keeping a commodious space and enough height of the operator compartment.

- Achieve a good balance between the performance upgrade and downsizing by newly developed $\mathrm{AC}$ motor and $\mathrm{AC}$ controller.

- Smooth, powerful and fine operability while travelling and loading due to the improvement of control logic.

- Excellent safety functions based on TOYOTA SAS (System of Active Stability TM).

- Improvement of wide variety of items to reduce operator's fatigue by improving workability.

\section{AC Motor Driven System}

The configuration of the AC motor driven system is shown in Fig. 1 and Fig. 2 shows the appearance of it and built-in capacitors.

To drive 2 motors for run and 1 motor for loading, the AC motor driven system of New Battery Forklift has 3 inverter circuits. And each inverter circuit is the same specification.
As a result, the component standardization was achieved, and the extendibility of the system became easy.

The inverter circuit is composed of the low-loss MOS-FET and the aluminum electrolytic capacitors (4 pieces per 1 circuit).

By changing the material of the inverter chassis from resin (conventional type) to aluminum (new type), the heat radiation of MOS-FET and the aluminum electrolytic capacitor have been greatly improved.

Therefore, the system achieved not only a great miniaturization but also high reliability by the optimized thermal design.

Fig. 3 shows the volume comparison of AC motor driver. The new AC motor drive system achieved $\Delta 72 \%$ downsizing compared to the conventional type.

\subsection{Features of New AC Motor Driver}

- Downsizing.

- High reliability.

- Adoption of the low-loss MOSFET.

- 6 in 1 module structure.

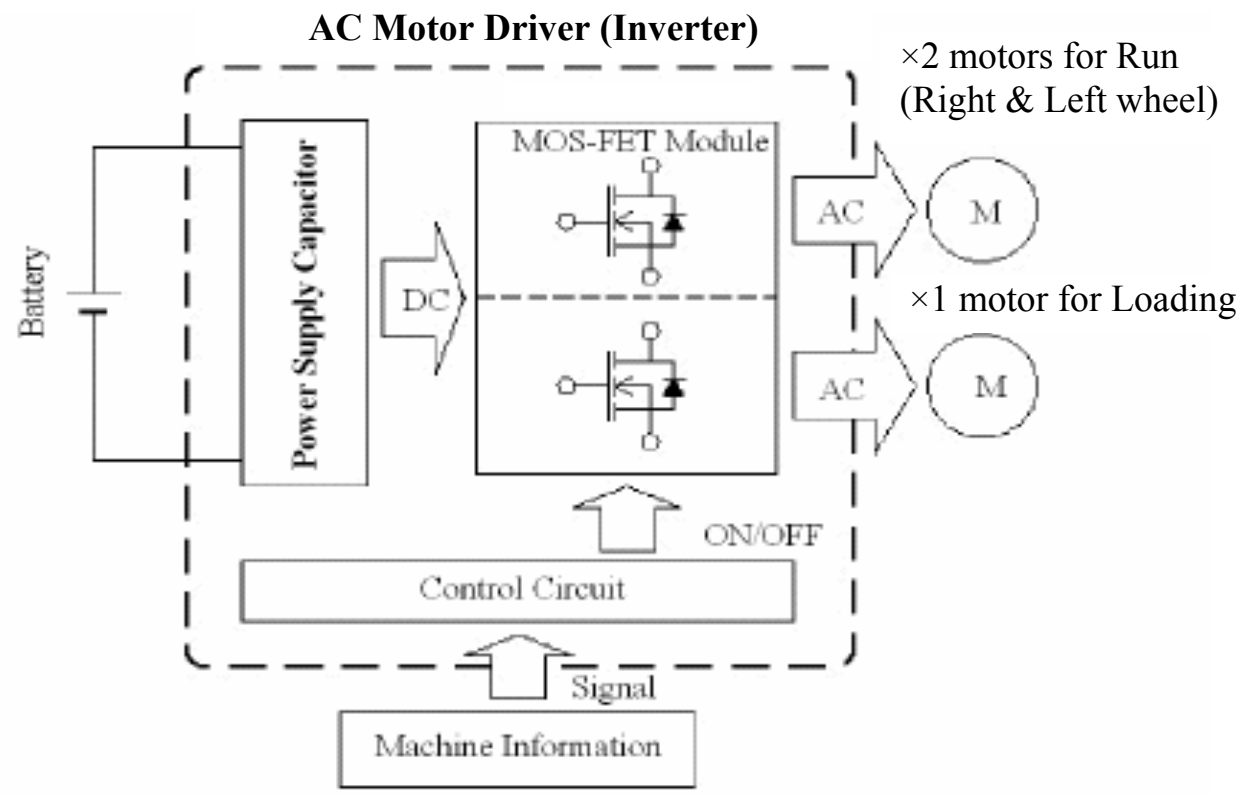

Fig. 1 The configuration of AC motor driven system 


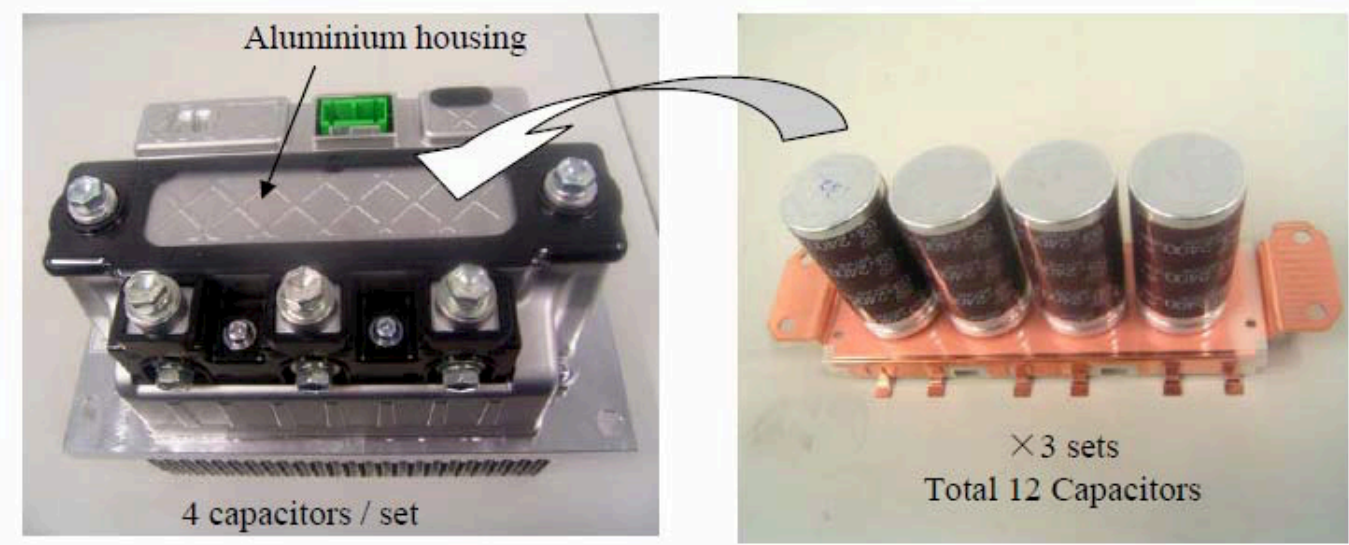

Fig. 2 The appearance of AC motor driver and built-in capacitors

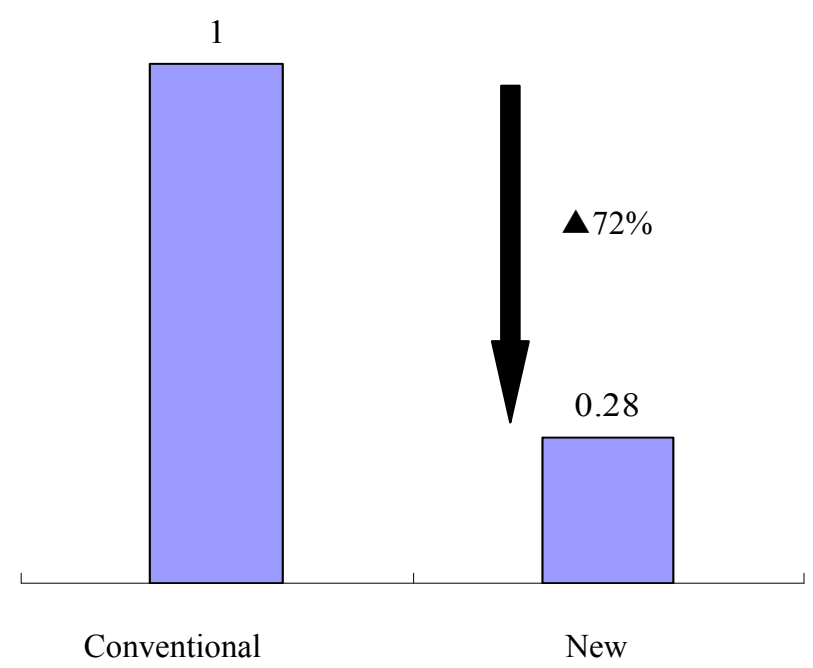

Fig. 3 The volume comparison of AC motor driver 


\section{Aluminium E-Capacitor for Inverter Circuit}

Downsizing and high output are strongly required for the capacitor mounted on the inverter. In order to realize this demand, NIPPON CHEMI-CON considers reducing capacitor internal resistance, specially the improvement of -40 degree C low-temperature characteristic, and optimizing radiation performance of capacitor based on the structure change of inverter chassis.

\subsection{ESR Reduction of Capacitor}

(Low temperature characteristics)

The internal resistance of the aluminium electrolytic capacitor consists of the electrolytic (electrolyte + separator) resistance ingredient and the resistance ingredient of electrode foil, and in order to improve especially the low temperature ESR, we must reduce the electrolytic resistance ingredient.
Ethyleneglycol(EG) and gamma-butyrolactone (GBL) are known as solvents of the electrolyte for aluminium electrolytic capacitors. In order to reduce the low-temperature characteristic, GBL system electrolyte is advantageous.

Then, we developed the new GBL system electrolyte, are combining it with the special separator and realized low ESR.

The ESR-frequency characteristic of the development product and the conventional product is shown in Fig.4. ESR characteristic of -40 degree $\mathrm{C}$ is dramatically improvable $(233 \mathrm{~m} \Omega \rightarrow 13.1 \mathrm{~m}$ $\Omega)$.

On the other hand, change of the sealing plate is needed with adoption of the GBL system electrolyte. The conventional phenolic resin laminate with rubber cannot be used due to less solvent resistance toward GBL. Then, we decide to adopt sealing plate made of phenol resin which is excellent in solvent resistance instead of conventional plate. The appearance is shown in Fig. 5. Change of the plate also made it possible to adopt more reliable TIG welding (arc welding) from the conventional resistance welding adopted as connection of a capacitor terminal and a bus bar. The connection state of capacitor terminal and bus bar after TIG is shown in Fig.6.

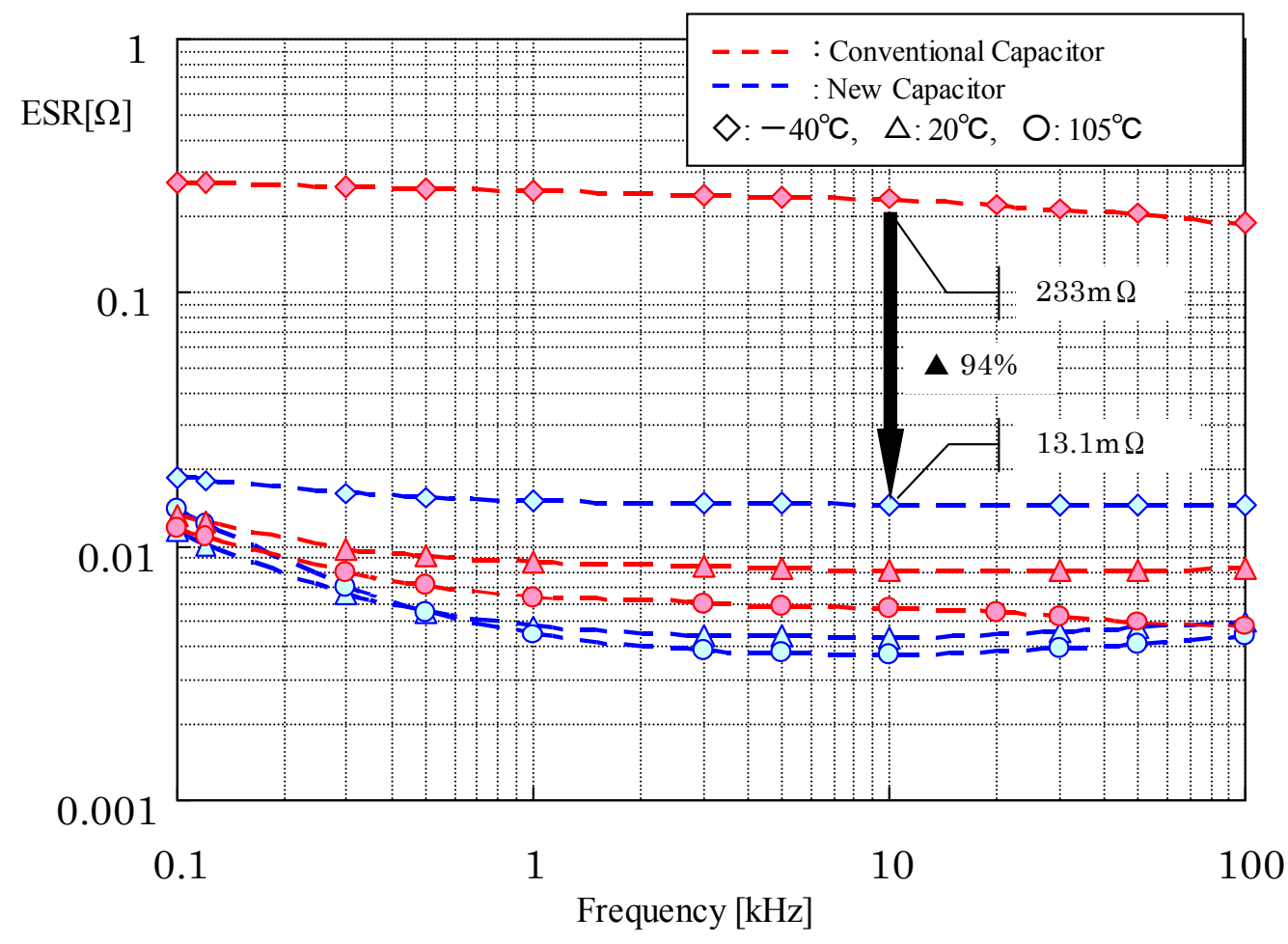

Fig.4 ESR characteristic of aluminium electrolytic capacitor 

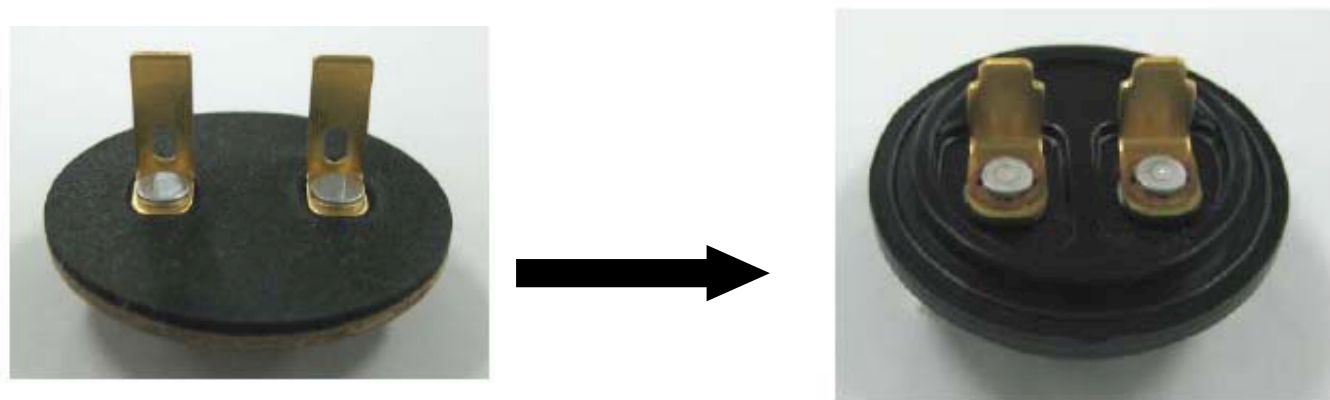

Fig.5 Change of electrolytic capacitor sealing plate

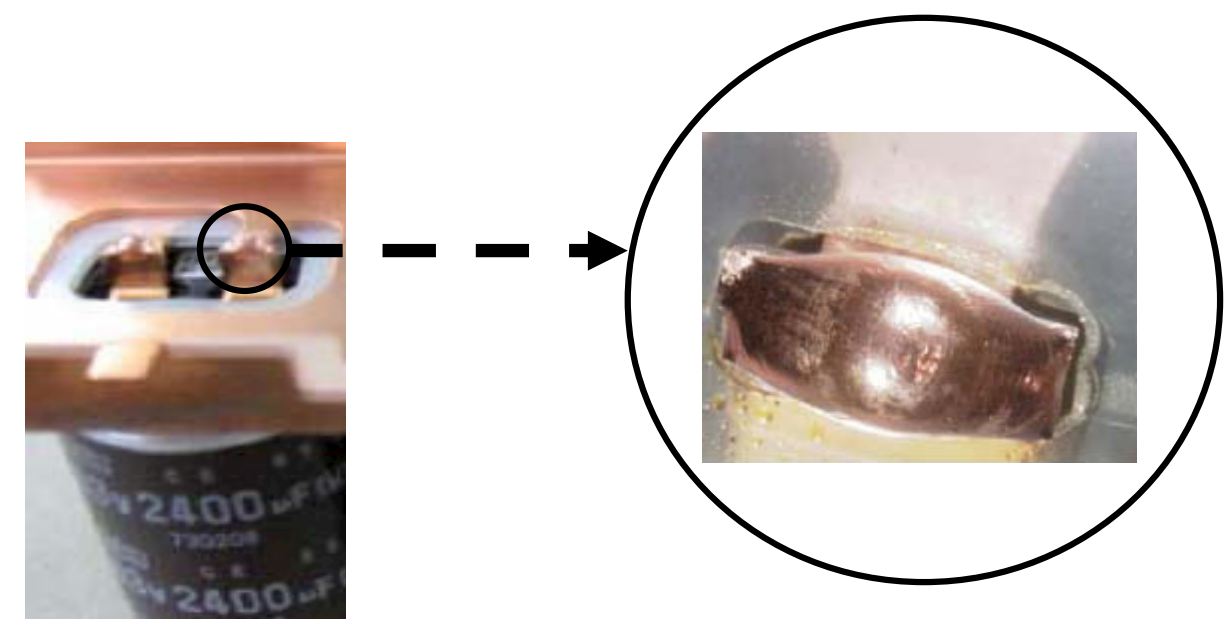

Fig.6 TIG welding appearance of capacitor terminal and bus bar

\subsection{Heat Radiation of Capacitor}

The greatest point of downsizing the capacitor for inverters is how to control temperature rise. Temperature rise control of a capacitor can be said that ESR reduction and coefficient of heat transfer increase are the effective method as it is defined with the following formula.

\section{$\Delta \mathrm{T}=\mathrm{Ir}^{2} \cdot \mathbf{E S R} / \beta \mathrm{A}$}

$\Delta \mathrm{T}:$ Temperature rise

Ir : Ripple current

ESR : Equivalent series resistance

$\beta$ : Coefficient of heat transfer

A : Total surface area of the heat transfer
The reduction of electrolyte resistance or electrode foil resistance are effective for reduction of ESR as described in 3-1.clause.

Moreover, improvement of capacitor radiation performance is to improve adhesion of a capacitor element and a case in order to decrease heat resistance of capacitor inside and to change cylindrical type shape of capacitors to ellipse ones. In this case, it is usual to examine heat generation of capacitors under non air-cooled environment. However, the actual environment of capacitors may accompany with forced cooling such as aircooling or water-cooling to take the heat from power devices. 
Therefore, we work on the improvement of radiation performance in consideration of actual capacitor environment upon joint development with TOYOTA INDUSTRIES CORP. Since the inverter developed by TOYOTA INDUSTRIES CORP. can be used for cooling off capacitors even though it has forced cooling system to cool off power devices, we adopt the structure to cool off the bottom of capacitor, which is able to adhere a capacitor to aluminium chassis of inverter module. Fig.7 is the photograph of the bottom of capacitor. Conventional products cannot ensure the adhesion to inverter chassis due to the vent on the bottom of cases and the bulged vent caused by the elevation of inner pressure.
However, the developed capacitor ensures the adhesion to inverter chassis by eliminating the vent from the bottom of case and improving strength of it. With this structure, it is possible to use the aircooling effect of inverter for cooling off capacitors as well because the bottom of capacitor does not bulge even though inner pressure of capacitor increases. Fig.8 is the result of capacitor temperature rise test in consideration of radial performance from aluminium chassis. By 20Arms / $10 \mathrm{kHz}$ ripple current is applied to capacitors, when the capacitors are not adhered to an aluminium chassis, the radial performance will be $16.6 \mathrm{deg}$, however, when the capacitors are adhered to an aluminium chassis, it will be $6.5 \mathrm{deg}$. $(\Delta 62 \%)$.

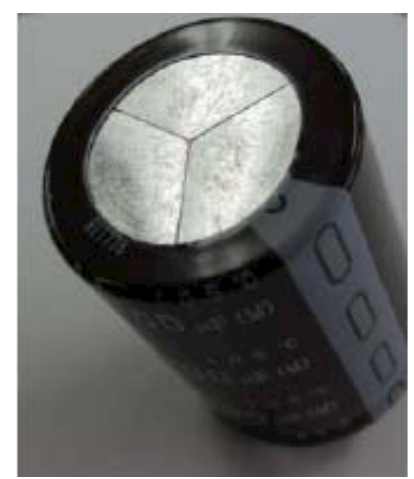

Conventional shape (pressure valve)

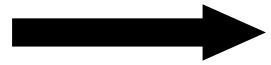

Fig.7 Bottom cooling structure of electrolytic

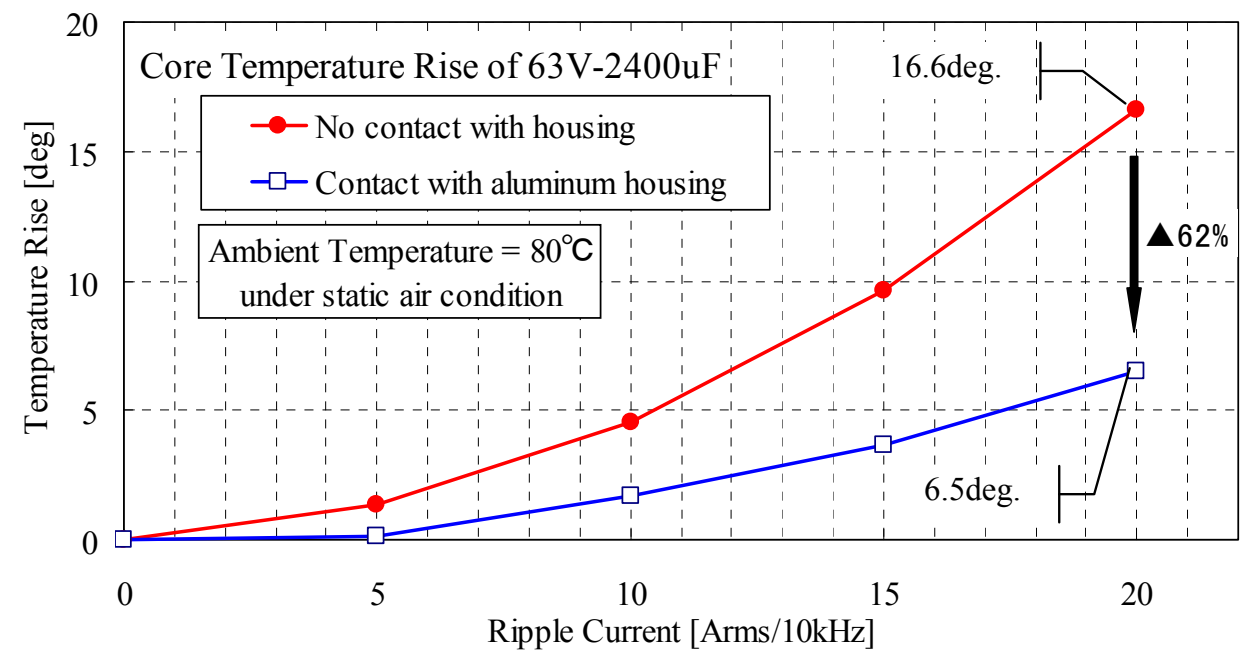

Fig.8 The comparison of capacitor temperature rise by the ripple electric current (cooling effect) 


\subsection{Endurance of Capacitor}

Fig.9 shows the reliability test results of the capacitor adopted this time.

Due to the load test with rated ripple current, sufficient durability of capacitor electric characteristics, such as capacitance rate, ESR and leakage current, is confirmed.
$<$ Test samples $>$

New Capacitor:

$63 \mathrm{~V} 2700 \mu \mathrm{F}(\varphi 30 \times 60 \mathrm{~L} \mathrm{~mm})$

$<$ Test Conditions $>$

$\checkmark: 105^{\circ} \mathrm{C}$ static air,

Ripple current $=14.5 \mathrm{Arms} / 10 \mathrm{kHz}$,

(No contact with housing)

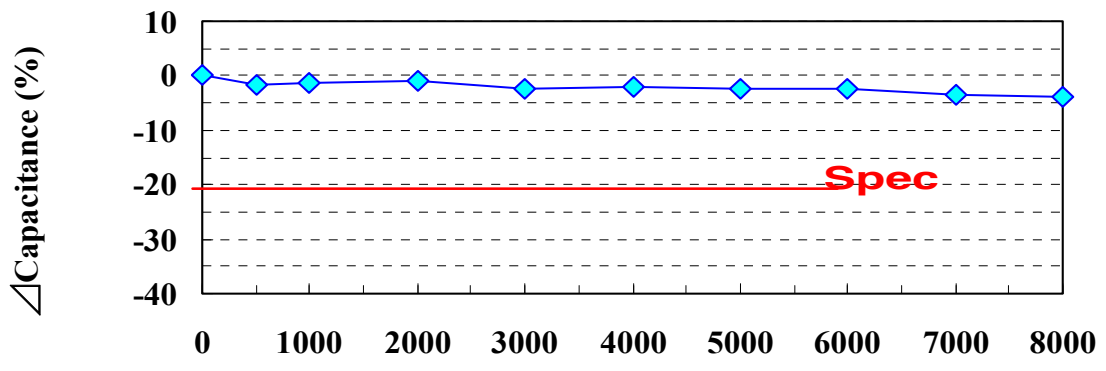

(Hours)

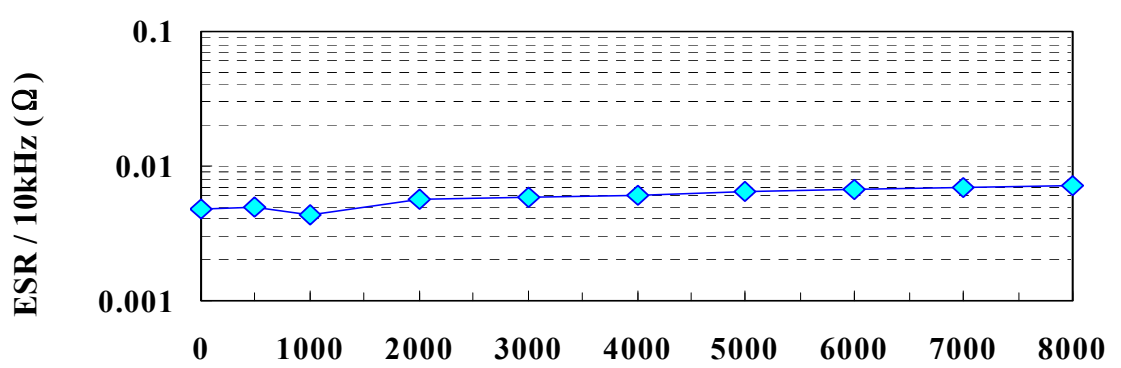

(Hours)

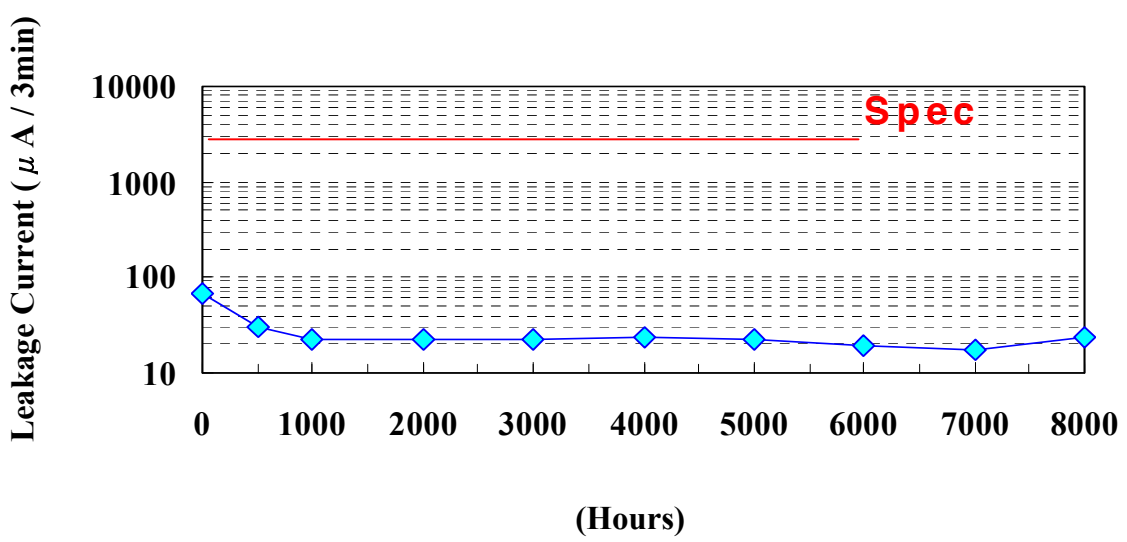

Fig.9 Reliability test results of the development capacitor 


\section{Conclusion}

\subsection{AC Motor Driver}

The new AC motor drive system achieved $\Delta 72 \%$ of downsizing by developing low-loss MOS-FET and downsized capacitors and adapting new structure and new method. In addition, high reliability of system is realized based on the optimal heat design, such as the improvement of radiation performance.

\subsection{Aluminium Electrolytic Capacitor}

The comparison between the developed capacitor and conventional one is shown in Table.1. ESR of the developed capacitor achieves the decrease of $\Delta 94 \%$ at low temperature $\left(-40^{\circ} \mathrm{C}\right)$ and $\boldsymbol{\Delta} 40 \%$ at high temperature $\left(105{ }^{\circ} \mathrm{C}\right)$ compared to the conventional capacitor. Moreover, $\boldsymbol{\Delta} 62 \%$ of the temperature rise reduction is confirmed compared to the conventional capacitor by adopting the structure of bottom cooling. From these results, the whole capacity of capacitor mounted on the inverter of new battery forklift is achieved $\Delta 47 \%$ of downsizing.

\begin{tabular}{|c|c|c|}
\hline & New Motor Drive system & Conventional system \\
\hline Size Ratio & $0.28(\mathbf{\Delta} 72 \%)$ & 1.0 \\
\hline Weight Ratio & $0.43(\mathbf{\Delta} 57 \%)$ & 1.0 \\
\hline
\end{tabular}

\begin{tabular}{|c|c|c|c|}
\hline & New Capacitor & Conventional type \\
\hline \multicolumn{2}{|c|}{ Capacitor rating } & $63 \mathrm{~V} 2,400 \mu \mathrm{F}$ & $100 \mathrm{~V} 2,700 \mu \mathrm{F}$ \\
\hline \multicolumn{2}{|c|}{ Capacitor size } & $\varphi 30 \times 60 \mathrm{~L}(\mathrm{~mm})$ & $\varphi 35 \times 50 \mathrm{~L}(\mathrm{~mm})$ \\
\hline \multirow{3}{*}{$\begin{array}{c}\text { ESR } \\
(\mathrm{m} \\
\Omega)\end{array}$} & $-40^{\circ} \mathrm{C}$ & $13.1 \mathrm{~m} \Omega(\mathbf{\Delta} 94 \%)$ & $233 \mathrm{~m} \Omega$ \\
\hline & $20^{\circ} \mathrm{C}$ & $4.6 \mathrm{~m} \Omega(\mathbf{\Delta} 43 \%)$ & $8.1 \mathrm{~m} \Omega$ \\
\hline & $105^{\circ} \mathrm{C}$ & $3.5 \mathrm{~m} \Omega(\mathbf{\Delta} 40 \%)$ & $5.8 \mathrm{~m} \Omega$ \\
\hline \multicolumn{2}{|c|}{ Quantity installed } & 12pcs / unit (4pcs x 3 sets) & 20pcs / unit \\
\hline \multicolumn{2}{|c|}{ Total volume } & 0.51 l $(\mathbf{\Delta} 47 \%)$ & 0.96 l \\
\hline \multicolumn{4}{|c|}{ Appearance } \\
\hline \multirow{2}{*}{\multicolumn{2}{|c|}{ Package structure }} & x 3 sets & \\
\hline & & Contact with aluminum chassis & No contact with chass \\
\hline
\end{tabular}

Table. 1 The comparison between the developed capacitor and conventional one 


\section{References}

[1] Kanji Ohta et al., "Development of Power Capacitors for Inverter-Driven Battery Forklift" EVS20, Aug. 2003

[2] Yoshihiro Fujita et al, "The power capacitors for realizing the downsized Hybrid System", EVS21 Di1-B1(1), April 2005

[3] Youichi Shida et al., "Development of Inverter and Power Capacitors for Mild Hybrid Vehicle (MHV) - Toyota Crown" EVS19 P2D201_042

[4] Yoshihiro Fujita et al, "The Development of Power Capacitor for "HIJET CARGO HYBRID”, EVS-22, October 2006

[5] Takao Kanno et al., "Flat type super high voltage power capacitors for hybrid airconditioner" EVS23, December 2007

\section{Authors}

Makoto Shimizu

Nippon Chemi-Con Co.

Products R\&D Headquarters

I am engaged in design work of the large aluminium electrolytic capacitors following the research of electrolyte for capacitors.

Yuichi Tanaka

Nippon Chemi-Con Co.

Automotive Electronics Promotion Department

I will propose the best solution of passive components after grasping the needs of our customers.

Yoshihiro Fujita

Nippon Chemi-Con Co.

Marketing Department

I study the market trends of automotive electronics and I support the product development and the promotion of our components.

\section{Shuichi Kitagawa}

Europe Chemi-Con Co.

Engineering / Marketing

I will provide the engineering support to the customers in Europe. I am in Nuremberg, Germany.

Toshiaki Nagase

Toyota Industries Co.

Engineering Department

I am engaged in development of controller for battery forklift.

Kazuyoshi Kontani

Toyota Industries Co.

Engineering Department

I am engaged in development of controller for battery forklift. 